\title{
Промени в подбора на пациентите \\ за кохлеарна имплантация
}

\author{
С. Върбанова, Д. Попова,Т. Попов, \\ С. Тодоров, О. Стоянов, И. Станчева \\ Медицински университет - София \\ Катедра УНГ-болести
}

\begin{abstract}
Резюме
Авторите представят развитието на проблема, основанията и резултатите от прилагането на оперативната интервенция кохлеарна имплантация за лечение на трайни дефицити в чуването. Разглеждат се новите индикации по отношение възрастта, запазване на остатъчния слух, генетичните слухови увреди, едностранната глухота, невропатията и необходимостта от двустранна кохлеарна имплантация при деца и възрастни.
\end{abstract}

\section{1. Въведение}

Пьрвата програма за КИ при деца се прилага в House Ear Institute през 1980. Оперирано момче на 9 години, а през 1982 вече 12 деца от 3,5 до 17 години. Имплантът House/3М получава одобрение от Food and Drug Administration за имплантации на възрастни през 1984 година, а на деца през 1986 г. През 1990 г. е оперирано дете на 2 години и до края на годината вече са оперирани повече деца от възрастни. В САЩ FDA, защитавайки здравето и правата на населението, има голямо влияние върху развитието на КИ, като се извършват много клинични проучвания по нейна инициатива, допринасящи за техническото им усъвършенстване. Технологичното усъвършенстване на КИ дава възможности за разширяване на критериите при подбора на пациенти. Промените при подбора на кандидатите са по отношение на остатъчния слух, намаляване на възрастта за КИ и прилагане на това лечение при аномалии на кохлеята.

\section{2. КИ при малки деца}

Широко разпространеният универсален слухов скрининг води до увеличаване на ранното откриване на слуховите загуби. Подобряването на ранната диагностика води и до нарастване на съпротивата срещу ранните интервенции. Вече има безспорни доказателства за предимствата на ранната КИ. Говорното развитие при децата започва от раждането и е почти завършено около 6-годишна възраст. Говорните умения, качествата на речта и експре- 
сивния и рецептивен речник се влияят от въ3можно най-ранното речево въздействие. Много години най-ниската възраст за КИ е 2-годишната възраст. От 2000 г. FDA приема възрастта 12 месеца като най-подходяща за тази оперативна интервенция. Повечето автори препоръчват уточняване на нивото на слуховите загуби около 6-месечна възраст и включване на децата в програмите за КИ, което дава възможност за достоверни оценки преди имплантацията на 12-месечна възраст.

Неспазването на този порядък дава възможност за опериране на деца без индикации и нужда от КИ.

Основанията за КИ на деца под 1 година трябва да се базират на данни от VRA (поведенческа аудиометрия), изследването на ОАЕ, честотно специфична ABR или ASSR, двустранна тимпанометрия и акустичен рефлекс. Изследването на говорна разбираемост в тази възрастова група остава несигурно, както и повечето езиково базирани тестове, които са неприемливи за деца под 1 година.

\section{3. КИ и запазване на слуха}

Част от изследванията показват, че запазването на остатъчния акустичен слух в оперираното ухо е реална цел при много пациенти с тежки високочестотни слухови загуби. Допълнителната електрическа стимулация към техния съществуващ акустичен слух може да подобри състоянието на пациентите. В допълнение запазването на акустичния слух може да има предимства пред традиционния КИ при разговор за подобро разпознаване на думи в шумна обстановка или възприемането на музика, както и в други акустични ситуации, когато лошата честотна резолюция на електрическата стимулация не е достатьчна.

Целта е запазване на съществуващия остатьчен акустичен слух за ниските честоти в ухото с КИ и добавяне на електрическа стимулация чрез КИ за липсващите високи честоти, за да се осигури по-добра говорна разбираемост (или друго слухово усещане) чрез тази комбинация.

Областите със загуба на част от вътрешните слухови клетки се определят като „мъртви зони“ и са причина за лоша говорна разбираемост. Тежките високочестотни слухови загуби често не могат да бъдат успешно повлияни чрез просто усилване. Запазването на слуха в оперираното ухо при животни се докладва още през 1990 г. През 1992 г. откриват, че разполагането на къс електрод при животни не предизвиква допълнителни увреди на тъканите дистално. Отчитането на почти нормални клик-евокирани ABR прагове при повечето от кохлеите при проучване от този период допуска, че слуховите клетки, апикално от имплантирания електрод, не само оцеляват, но и могат да функционират почти нормално.

През 1990 г. група от Университета в Iowa започва да имплантира КИ с нов дизайн с модифициран интракохлеарен електрод, който е с помальк диаметър и дължина 6 мм при пациенти с използваем остатьчен слух за ниски честоти.

Запазването на остатъчния слух се оказва практично и ефективно решение за тежките високочестотни слухови загуби. Така може да се избегнат недостатьците на традиционната, само електрическа стимулация с дълъг електрод КИ. Предимствата на $\mathrm{A}+\mathrm{E}$ методика дават като резултат по-добра честотна резолюция, осигурена от остатъчния слух, в сравнение с електрическата стимулация. Предимствата на А + Е методиката са по-демонстративни в ситуации, когато честотната резолюция е важна като разчитане на речта при околен шум и възприемането на музика.

\section{4. КИ при едностранна глухота}

До сега възможностите за лечение на едностранната глухота бяха ограничени като слухопротезиране CROS или BAHA. КИ дава нови възможности за лечение на пациентите с едностранна глухота. Arndt et al. в проучване сравняват 6месечни предоперативни резултати от ползване на CROS или BAHA с тези от последвала КИ на същото ухо при пациенти. Авторите откриват, че КИ подобряват слуховите възможности при хора с едностранни слухови загуби. Използването на КИ не влияе на говорната разбираемост на нормално чуващото ухо. Тези данни допускат, че бинауралната интеграция на електрическа и акустична стимулация е възможна дори и при пациенти с такава патология.

\section{5. КИ при едностранна глухота и тинитус}

Тинитусът е често срещано състояние, което трудно се повлиява от лечение. Най-често използвани са слухова стимулация и когнитивно -поведенческа терапия за подобряване на хаби- 
туацията. Много причинно насочени терапевтични стратегии имат неуспех поради необходимостта от осъзнаването на проблема с звуковата перцепция. Въпреки че патофизиологията на T остава ненапълно разбрана, се увеличават доказателствата, че е свързан с промени във функционирането на невроните в централната слухова система. По подобие на фантомната лимбична болка Т като една слухова фантомна перцепция може би е свързан с неуспешни опити на мозъка за реорганизация поради разстроен сензорен вход. Това се потвърждава от факта, че слуховата загуба е много важен рисков фактор за развитието на Т и че повечето хора с внезапна загуба на слуха имат $\mathrm{T}$.

Терапевтичните стратегии, които специфично компенсират слуховата загуба или възприятието на входа чрез слухова протеза, приемат, че се намаляват оплакванията от Т. (32). При глухи пациенти с Т лечението му се основава на възможната акустична стимулация.

Актуални са дискусиите за прилагането на КИ за облекчаване и повлияване на Т при пациенти с едностранна глухота. Има съобщения, които подкрепят патофизиологичния модел за обяснението на хроничния Т като неуспешен опит за кортикална реорганизация поради периферна деаферентизация (36). Като последица от това възстановяването на периферния сензорен вход може дълго да има положителен ефект върху Т чрез реорганизация на централната слухова НС. Такъв механизъм може да се наблюдава 3 месеца след КИ. Друго възможно обяснение е маскирането на Т като последица от увеличаването на слуховата информация след КИ.

Оперативната намеса травмира остатъчните структури в кохлеята, което може да е от полза за пациенти, при които абнормалната активност на слуховите клетки се оказва пусков механизъм за Т. При тези пациенти се очаква непосредствен следоперативен ефект от деструкцията, който може да се появи независимо от активацията на имплантната система.

В обобщение безпокоящият, сьпровождащ внезапната едностранна слухова загуба тинитус може да бъде нова индикация за КИ, което дава шанс за потискането му при някои пациенти.

\section{6. Генетична слухова загуба и КИ}

Вродените причини са около $60 \%$ от всички прелингвални слухови загуби. Литературните данни не са съвсем категорични поради все още малкия брой наблюдавани пациенти.

\subsection{Connexin 26 and 30}

Тези мутации се определят като $25 \%$ от несиндромалните автозомно-рецесивни слухови загуби, което ги прави най-честа причина за несиндромалната вродена слухова загуба.

Доминантната Сх26 мутация рядко се асоциира със синдромни заболявания с кожни разстройства напр. keratitis ichthyosis deafness syndrome, palmoplantar keratoderma with deafness (38). Конексинът е протеин, който участва в образуването на конексон, а 2 конексона образуват интрацелуларен цепковиден контакт (канал) за връзка между клетките и поддържане на транспортен калиев градиент в спиралния лигамент и васкуларната стрия. При дефект на тези протеини може да се натрупа Ка и този проблем в циркулацията да предизвика дисфункция и дегенерация на дисфункция и дегенерация на ресничестите клетки (39). Друга роля на Сх26 каналите е може би Са мобилизация във физиологичната регулация на кохлеата. Една от найчестите мутации е $30 \mathrm{delG}$, въпреки че са известни по-вече от 100 мутации на този конексин. Анализ на темпоралните кости при хетерозиготни мутации на Сх26 установява интактни клетки на спиралния ганглий, без неврални дегенерации, липса на ресничести клетки в Кортиевия орган и stria vascularis (41), което може да обясни добрите резултати след КИ, тъй като тези пациенти имат по-голям интегритет между периферната и централна част на слуховата система. Данните от проучвания сочат по добри резултати след КИ по отношение на възприемане и развитие на говор.

\subsection{Usher Syndrome}

Автозомно-рецесивен синдром, една от найчестите причини за слепо-глухота при хората. Прогресиращ retinitis pigmentosa, с последваща дегенерация на ретината, загуба на нощно виждане след 10-годишна възраст и възможна слепота. Изследвания на темпоралната кост - тежки дегенерации в основната витка, атрофия на stria vascularis, намаляване на клетките в спиралния ганглий. Значително намаляване на кохлеарните неврони до 68\%. Пациентите могат да имат остатъчен нискочестотен слух, без резултат от акустично усилване. КИ възможно най-рано за 
по-добра говорна разбираемост, преди загуба на зрение. Най-добри резултати за независим живот преди 3-годишна възраст.

\section{3. Митохондриални разстройства}

Митохондриалните (MtDNA) мутации са предимно свързани с бременността, тъй като митохондриалното ДНК на ембриона е почти пълно копие на това на майката. КИ е подходяща, тъй като SNHL има при 40-70\% от пациентите с митохондриални увреди. При тези пациенти слуховата загуба може да е синдромална и несиндромална. Несиндромалната SNHL e свързана с ототоксичния страничен ефект на аминоглюкозидите и доминиращи мутации през бременността (MtDNA) при по-вече от 50\% от пациентите.

\subsection{The Waardedenburg Syndrome}

Този синдром се установява при 1 на 40000 живи раждания и представлява 2-5\% от вродената глухота при децата. (59) Основната причина е увреда в меланогенезата, със слухови увреди до $90 \%$. Проучвания на темпоралната кост показват атрофия на Кортиевия орган и stria vascularis. Лечението е слухопротезиране или КИ с много добри резултати. Важно е да се отбележи, че при тези пациенти се увеличава честотата на слуховата невропатия!!!

\section{7. Двустранна кохлеарна имплантация}

Нашето звуково обкръжение е шумно и изпълнено със звуците от разнообразни източници, които се предизвикателство за слуховия анализатор. Системата две уши е отговорна за осигуряване на разделянето на различни сигнали от конкуриращи се звуци и за възможността за идентификация на източници на звука от слушатели с нормален слух. Чуването с двете уши е резултат от интеграцията между входните сигнали от двете уши и слуховите пътища. Последица от това е говорната разбираемост при наличието на конкуриращи се звуци. Добре е известно, че когато чуваме само с едното ухо, локализацията на звука става много трудна.

Установени са 3 първични ефекта от възприемането при двустранното чуване:

- ефекта на сянката на главата - появява се, когато говорьт и шумът са пространствено разделени. Има голямо значение за чуването с 2 КИ.
- ефекта на бинауралната сумация

- squelch effect - възможността за комбинация на шума от ухото с по-лошо съотношение сигнал/шум с шума от ухото с по-добро съотношение. Така мозъкът сравнява разликите във времето, амплитудите и спектралната информация между двете уши и звуците се отделят като слухови обекти.

Пациентите с едностранна КИ по-лошо идентифицират звукови източници и затруднено възприемат речта в шумна обстановка, докато тези с двустранна КИ могат да локализират и разпознават говора в шум.

В литературата са описани много пациенти с двустранна КИ и авторите споделят резултатите на пациентите за разбиране на говор при наличието на конкурентни стимули и предимството за пространствено разделяне на таргет сигнала и реч. Специалистите концентрират вниманието се върху трудностите при едностранна КИ в ежедневието поради невъзможността за локализация на звука и чуване и разбиране при шум. Ново предизвикателство е дилемата „Последователна или едноетапна КИ“. При деца нормално развитие на кортикалната активност има, когато между двете КИ има минимална разлика. Като оптимален е установен периодът от 3-4 години.

\section{8. Невропатия и КИ}

Слуховата невропатия или десинхронизация (AN/AD) се характеризира с тежка невросензорна загуба на слуха със запазена функция на външните слухови клетки, но с разстроена аферентната активност в слуховия нерв и централните слухови пътища. Честотата ѝ е $10-14 \%$ от децата с тежка невросензорна загуба на слуха. От изследванията: ОАЕ налични поради нормалната кохлеарна пренервална активност. Кохлеарните микрофонни потенциали са непроменени.

Разстройствата на слуховите пътища се допускат поради липсата или тежки деформации на електрическите потенциали от слуховия нерв (общ акционен потенциал) и стволови евокирани потенциали. Има някои хипотези за обяснението на слуховата невропатия или десинхронизация (AN/AD): лезии на вътрешните слухови клетки, в синапсите между тези клетки и тип 1 фибрите на слуховия нерв и в самия слухов нерв.

Клиниката се владее от по-лошата говорна разбираемост, несъответстваща на ТПА, безрезул- 
татно използване на НА, неразвиване на говор при прелингвално начало.

Дебатира се КИ поради топиката на лезията чрез заобикаляне на вътрешните слухови клетки и директна стимулация върху нерва. Но ако процеси като демиелинизация ангажират нерва, няма възможност за електрическа както и акустична стимулация. Много клиницисти са въздържани по отношение ефективността на КИ при тези състояния. Допуска се, че $75 \%$ от случаите са резултат от оцеляването на външние слухови клетки, когато е компрометирана функцията на вътрешните. Останалата част се дължи на дисфункция в аферентните синапси, слуховия нерв, кохлеарните ядра, пьтищата в ствола на мозъка и централната слухова система. Съобщават се резултати от КИ при деца 6 м след операция, които не са в състояние да участват в тестване поради изоставане в НПР. Някои деца не достигат желания ефект от КИ

\section{Книгопис}

1. L. Eisenberg and W. House, ,Initial experience with the cochlear implant in children", Annals of Otology, Rhinology and Laryngology Supplement, vol. 91, no. 2, pp. 67-73, 1982.

2. S. B. Waltzman and J. T. Roland Jr., Cochlear Implant Candidates in Cochlear Implants, Thierme Medical Publishers, New York, NY, USA, 2006.

3. Cheng, G. Grant, and J. Niparko, „Meta-analysis of pediatric cochlear implant literature", Annals of Otology, Rhinology and Laryngology, vol. 108, no. 4, pp. 124-128, 1999.

4. P. Kileny, T. Zwolan, and C. Ashbaugh, ,The influence of age at implantation on performance with a cochlear implant in children", Otology and Neurotology, vol. 22, no. 1, pp. 42-46, 2001.

5. M. P. Moeller, „Early intervention and language development in children who are deaf and hard of hearing", Pediatrics, vol. 106, no. 3, pp. E43-E52, 2000.

6. L. James and B. C. Papsin, ,Cochlear implant surgery at 12 months of age or younger“, Laryngoscope, vol. 114, no. 12, pp. 2191-2195, 2004.

7. S. Arndt, A. Aschendorff, R. Laszig et al., „Comparison of pseudobinaural hearing to real binaural hearing rehabilitation after cochlear implantation in patients with unilateral deafness and tinnitus“, Otology and Neurotology, vol. 32, no. 1, pp. 39-47, 2011.

8. D. M. Valencia, F. L. Rimell, B. J. Friedman, M. R. Oblander, and J. Helmbrecht, ,Cochlear implantation in infants less than 12 months of age", International Journal of Pediatric Otorhinolaryngology, vol. 72, no. 6, pp. 767-773, 2008.

9. R. T. Miyamoto, M. J. Hay-McCutcheon, K. I. Kirk, D. M. Houston, and T. Bergeson-Dana, „Language skills of profoundly deaf children who received cochlear implants under 12 months of age: a preliminary study“, Acta Oto-Laryngologica, vol. 128, no. 4, pp. 373-377, 2008.

10. J. T. Roland Jr., M. Cosetti, K. H. Wang, S. Immerman, and S. B. Waltzman, „Cochlear implantation in the very young child: longterm safety and efficacy“, Laryngoscope, vol. 119, no. 11, pp. 2205-2210, 2009.

11. C. W. Turner, L. A. J. Reiss, and B. J. Gantz, „Combined acoustic and electric hearing: preserving residual acoustic hearing“" Hearing поради проблем при електрически индуцираната неврална синхронизация, свързаните с това и други здравни проблеми и комбинацията им.

\section{0. Заключение}

През последните години индикациите и критериите за КИ се промениха. За постигане на оптимален ефект е необходима ранна имплантация при децата с прелингвална глухота. Допълнителните увреждания с определена тежест не бива да бъдат контраиндикации за КИ. В наши дни подходящи за КИ са и хората с остатьчен слух. Комбинираната електроакустична стимулация е подходяща при функциониращи ниски честоти. Двустранната КИ става стандартна през последните 10 години. Обещаващи са и резултати при едностранни глухоти, съпроводени с дразнещ шум.

Research, vol. 242, no. 1-2, pp. 164-171, 2008.

12. J. Xu, R. K. Shepard, R. E. Milllard, and G. M. Clark, „Chronic electrical stimulation of the auditory system at high stimulus rates: a physiological and histopathological study“, Hearing Research, vol. 105, pp. 1-29, 1997.

13. V. Hodges, J. Schloffman, and T. Balkany, „Conservation of residual hearing with cochlear implantation", American Journal of Otology, vol. 18, no. 2, pp. 179-183, 1997.

14. Von Ilberg, J. Kiefer, J. Tillein et al., „Electric-acoustic stimulation of the auditory system“, ORL, vol. 61, no. 6, pp. 334-340, 1999.

15. W. Gstoettner, J. Kiefer, W.-D. Baumgartner, S. Pok, S. Peters, and O. Adunka, ,Hearing preservation in cochlear implantation for electric acoustic stimulation", Acta Oto-Laryngologica, vol. 124, no. 4, pp. 348-352, 2004.

16. J. Kiefer, M. Pok, O. Adunka et al., „Combined electric and acoustic stimulation of the auditory system: results of a clinical study“, Audiology and Neuro-Otology, vol. 10, no. 3, pp. 134-144, 2005.

17. C. James, K. Albegger, R. Battmer, S. Burdo, N. Deggouj, O. Deguine, et al., „Preservation of residual hearing with cochlear implantation: how and why“, Acta Oto-Laryngologica, vol. 125, no. 5, pp. 481-491, 2005.

18. J. J. Eggermont, „Pathophysiology of tinnitus“, Progress in Brain Research, vol. 166, pp. 19-35, 2007.

19. L. del Bo and U. Ambrosetti, „Hearing aids for the treatment of tinnitus“, Progress in Brain Research, vol. 166, pp. 341-345, 2007.

20. A. Buechner, M. Brendel, A. Lesinski-Schiedat et al., „Cochlear implantation in unilateral deaf subjects associated with ipsilateral tinnitus“, Otology and Neurotology, vol. 31, no. 9, pp. 1381-1385, 2010.

21. T. Kleinjung, T. Steffens, J. Strutz, and B. Langguth, „Curing tinnitus with a Cochlear Implant in a patient with unilateral sudden deafness: a case report", Cases Journal, vol. 2, no. 5, article 7462, 2009.

22. S. Wiley, D. Choo, J. Meinzen-Derr, L. Hilbert, and J. Greinwald, „GJB2 mutations and additional disabilities in a pediatric cochlear implant population", International Journal of Pediatric 
Otorhinolaryngology, vol. 70, no. 3, pp. 493-500, 2006.

23. R. J. Vivero, K. Fan, S. Angeli, T. J. Balkany, and X. Z. Liu, "Cochlear implantation in common forms of genetic deafness", International Journal of Pediatric Otorhinolaryngology, vol. 74, no. 10, pp. 1107-1112, 2010.

24. X. Z. Liu, S. I. Angeli, K. Rajput et al., „Cochlear implantation in individuals with Usher type 1 syndrome", International Journal of Pediatric Otorhinolaryngology, vol. 72, no. 6, pp. 841-847, 2008.

25. R. Sinnathuray, V. Raut, A. Awa, A. Magee, and J. G. Toner, „A review of cochlear implantation in mitochondrial sensorineural hearing loss“", Otology and Neurotology, vol. 24, no. 3, pp. 418426, 2003.

26. S. Usami, S. Abe, J. Akita et al., „Prevalence of mitochondrial gene mutations among hearing impaired patients", Journal of Medical Genetics, vol. 37, no. 1, pp. 38-40, 2000

27. H. Pau, W. P. Gibson, K. Gardner-Berry, and H. Sanli, ,Cochlear implantations in children with Waardenburg syndrome: an electrophysiological and psychophysical review“, Cochlear Implants International, vol. 7, no. 4, pp. 202-206, 2006

28. K. D. Brown and T. J. Balkany, „Benefits of bilateral cochlear implantation: a review", Current Opinion in Otolaryngology and Head and Neck Surgery, vol. 15, no. 5, pp. 315-318, 2007.

29. P. M. Zurek, „A note on onset effects in binaural hearing“, Journal of the Acoustical Society of America, vol. 93, no. 2, pp. 1200 1201, 1993.

30. R. Litovsky, A. Parkinson, J. Arcaroli, and C. Sammeth, „Simultaneous bilateral cochlear implantation in adults: a multicenter clinical study“, Ear and Hearing, vol. 27, no. 6, pp. 714-731, 2006.

31. B. J. Gantz, R. S. Tyler, J. T. Rubinstein et al., „Binaural cochlear implants placed during the same operation", Otology and Neurotology, vol. 23, no. 2, pp. 169-180, 2002.

32. J. Müller, F. Schon, and J. Helms, „Speech understanding in quiet and noise in bilateral users of the MED-EL COMBI 40/40+ cochlear implant system“, Ear and Hearing, vol. 23, no. 3, pp. 198-206, 2002.

33. H. Kuhn-Inacker, W. Shehata-Dieler, J. Muller, et al., „Bilateral cochlear implants: away to optimize auditory perception abilities in deaf children?" International Journal of Pediatric Otorhinolaryngology, vol. 68, pp. 1257-1266, 2004.

34. T. Balkany, A. Hodges, F. Telischi et al., „William House Cochlear Implant Study Group: position statement on bilateral cochlear implantation“, Otology and Neurotology, vol. 29, no. 2, pp. 107108, 2008.

35. L. G. Potts, M. W. Skinner, R. A. Litovsky, M. J. Strube, and F. Kuk, „Recognition and localization of speech by adult cochlear implant recipients wearing a digital hearing aid in the nonimplanted ear (bimodal hearing)", Journal of the American Academy of Audiology, vol. 20, no. 6, pp. 353-373, 2009.

36. K. A. Gordon, D. D. E. Wong, and B. C. Papsin, „Cortical function in children receiving bilateral cochlear implants simultaneously or after a period of interimplant delay“, Otology and Neurotology, vol. 31, no. 8, pp. 1293-1299, 2010.

37. A. Starr, T. W. Picton, Y. S. Sininger, L. J. Hood, and C. I. Berlin, „Auditory neuropathy“, Brain, vol. 119, no. 3, pp. 741-753, 1996.

38. G. Rance and E. J. Barker, ,Speech perception in children with auditory neuropathy/dyssynchrony managed with either hearing aids or cochlear implants", Otology and Neurotology, vol. 29, no. 2, pp. 179-182, 2008.

39. E. Buss, R. F. Labadie, C. J. Brown, A. J. Gross, J. H. Grose, and H. C. Pillsbury, „Outcome of cochlear implantation in pediatric auditory neuropathy“, Otology and Neurotology, vol. 23, no. 3, pp. 328-332, 2002.

40. H. F. Teagle, P. A. Roush, J. S. Woodard et al., „Cochlear implantation in children with auditory neuropathy spectrum disorder", Ear and Hearing, vol. 31, no. 3, pp. 325-335, 2010.

41. H. J. Neville, D. Bavelier, D. Corina et al., „Cerebral organization for language in deaf and hearing subjects: biological constraints and effects of experience", Proceedings of the National Academy of Sciences of the United States of America, vol. 95, no. 3, pp. 922-929, 1998.

42. J. E. Mossop, M. J. Wilson, D. M. Caspary, and D. R. Moore, „Down-regulation of inhibition following unilateral deafening“, Hearing Research, vol. 147, no. 1-2, pp. 183-187, 2000. View at Publisher · View at Google Scholar · View at Scopus

43. J. J. Eggermont, ,Role of auditory cortex in noise and drug-induced tinnitus“, American Journal of Audiology, vol. 17, no. 2, pp. S162-S169, 2008

44. P. A. Leake, O. Stakhovskaya, G. T. Hradek, and A. M. Hetherington, „Factors influencing neurotrophic effects of electrical stimulation in the deafened developing auditory system", Hearing Research, vol. 242, no. 1-2, pp. 86-99, 2008. View at Publisher · View at Google Scholar · View at PubMed · View at Scopus

45. J. B. Fallon, D. R. F. Irvine, and R. K. Shepherd, „Cochlear 